\title{
Different Roles of $\beta$-N-Acetylhexosaminidase in Metabolism
}

\section{Veronika Hýsková* and Helena Ryšlavá}

Department of Biochemistry, Charles University in Prague, Czech Republic

\section{Letter to the Editor}

$\beta$-N-acetylhexosaminidases (EC 3.2.1.52,) are ubiquitous enzymes, present in all organisms. These enzymes catalyze the hydrolysis of $\mathrm{N}$-acetylglucosamine (GlcNAc) or N-acetylgalactosamine (GalNAc) from non-reducing end of oligosaccharides, glycoproteins, glycolipids, and other glycoconjugates. The functions of these enzymes greatly differ between individual organisms, cells and compartments.

Human $\beta$-N-acetylhexosaminidases are involved in lysosomal catabolism of glycosphingolipids (gangliosides), essential membrane components of eukaryotic cell surface [1]. The mutations in genes for $\beta-\mathrm{N}$-acetylhexosaminidase lead to its reduced activity and to a series of fatal inherited metabolic disorders including Tay-Sachs' and Sandhoff's diseases. As a consequence of the reduced activity or absence of $\beta-\mathrm{N}$ acetylhexosaminidase, the brain cell lysosomes become engorged with indigestible substrates and child patients begin to suffer seizures, blindness, and degeneration of motor and mental performance and dies within a few years [2]. In mammalian mast cells, rather than in the lysosome. most of the $\beta-\mathrm{N}$-acetylhexosaminidase is localized in the granules, rather in the lysosome. Therefore, $\beta-\mathrm{N}$-acetylhexosaminidase is used as a typical marker of mast cell degranulation, which is related to allergic reactions [3].

During cell growth bacterial $\beta$ - $\mathrm{N}$-acetylhexosaminidases are associated with membrane degradation and recyclation of murein, peptidoglycane of the cell wall [4]. $\beta-\mathrm{N}$-acetylhexosaminidase from pathogenic bacteria could modify the surface of the host cell and thus participate in cell adhesion. Moreover, bacterial enzymes are associated with degradation of molecules serving for nutrition $[5,6]$. Not only bacteria but also yeast and protozoa can use the aminosugars like GlcNAc (product of $\beta$-N-acetylhexosaminidases treatment) as the sole carbon source. For example, Candida albicans can obtain GlcNAc during host organ colonization by secreting $\beta-\mathrm{N}$-acetylhexosaminidases via degradation of hyaluronic acid, which is a large polysaccharide composed of repeating disaccharide units of glucuronic acid and GlcNAc [7].

$\beta$-N-acetylhexosaminidases play an important role also in fungal metabolism, growth, and morphogenesis. The fungal cell wall consists of chitin, which can be degraded by endochitinases in cooperation with $\beta$-N-acetylhexosaminidase. Extracellular $\beta$-N-acetylhexosaminidases participate in competition with other fungal organisms $[8,9]$.

The functions of $\beta$-N-acetylhexosaminidases in plants are less known and studied. The suggested functions could be summarized into three groups. Firstly, $\beta$-N-acetylhexosaminidase participates in physiological processes such as seed germination and fruit ripening. In dry or germinating seeds $\beta$ - $\mathrm{N}$-acetylhexosaminidase is highly active and is considered to function in the degradation of reserve glycoproteins $[10,11]$. In tomato, capsicum and peach fruits $\beta-\mathrm{N}$ acetylhexosaminidase and $\alpha$-mannosidase activity is presumed to play a role in ripening and softening of fruits by releasing of free $\mathrm{N}$-glycans affecting ethylene biosynthesis [12-15]. Secondly, $\beta-\mathrm{N}$ acetylhexosaminidase (such as vacuolar and plasma membrane isoform in Arabidopsis thaliana) can participate in the generation of paucimannosidic oligosaccharides in glycoproteins, which are typically found in plants and invertebrate [16]. These structures are characterized by the presence of fucose and/or xylose, which can be transferred to the oligosaccharide core only after removal of the terminal GlcNAc (catalyzed by $\beta$-N-acetylhexosaminidase) from the complex oligosaccharide. It is interesting that this step of $\mathrm{N}$-glycan processing occurs in plants in vacuole rather than Golgi apparatus.

Finally, since chitinolytic activity, it is proposed that the function of some plant $\beta-\mathrm{N}$-hexosaminidases is related to defense responses against fungal and insect pathogens with chitin exoskeletal structure. Latex from different plants, which is secreted as a defense against predators, contains proteases, chitinases and other glycosidases, among which the activity of $\beta-\mathrm{N}$-acetylhexosaminidase was the highest $[10,17]$. $\beta-\mathrm{N}$ acetylhexosaminidase could participate together with chitinases in the chitinolytic system $[18,19]$. However, there are many differences in the ability of plant $\beta-\mathrm{N}$-acetylhexosaminidases to degrade chitooligomers. Some plant $\beta$-N-acetylhexosaminidases (such as from Arabidopsis thaliana, wheat, jack bean) prefer longer chitooligosaccharides to shorter ones $[16,20]$. Also tobacco $\beta-\mathrm{N}$-acetylhexosaminidase is able to degrade chitooligomers; N, N'-diacetylchitobiose and N, N', N"triacetylchitotriose with the reaction rate reduced only to $60 \%$ and $34 \%$, respectively compared to artificial substrate pNP-GlcNAc [21]. The highest reaction rate and the highest affinity to the substrate is usually achieved with $p \mathrm{NP}-\mathrm{GlcNAc}$, which is commonly used for easy colorimetric $\beta-\mathrm{N}$-acetylhexosaminidase activity determination. On the other hand, the testing of reaction rate in the presence of chitooligomers is more complicated, because the products must be chromatographically separated and for the sensitive quantification they are often labeled by fluorescent tag that can also affect properties of the substrate. Another alternative is the separation of products by capillary electrophoresis, which enables quick analysis in very small reaction volumes $[21,22]$.

\section{References}

1. Wendeler M, Sandhoff K (2009) Hexosaminidase assays. Glycoconj J 26: 945 952.

2. Campbell NA, Reece JB (2008) Biology (8thedn) Pearson Education.

3. Fukuishi N, Murakami S, Ohno A, Yamanaka N, Matsui N, et al. (2014) Does $\beta$-hexosaminidase function only as a degranulation indicator in mast cells? The primary role of $\beta$-hexosaminidase in mast cell granules. J Immunol 193: 18861894.

4. Cheng Q, Li H, Merdek K, Park JT (2000) Molecular characterization of the $\beta$ $-\mathrm{N}$-acetylglucosaminidase of Escherichia coli and its role in cell wall recycling. J Bacteriol 182: 4836-4840.

*Corresponding author: Veronika Hýsková, Assistant Professor, Department of Biochemistry, Charles University in Prague, Hlavova 2030, Czech Republic E-mail: veronika.hyskova@natur.cuni.cz

Received: October 12, 2015; Accepted: October 13, 2015; Published Octobe 17,2015

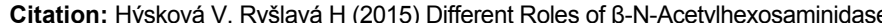
in Metabolism. Biochem Anal Biochem 4: 215. doi:10.4172/2161-1009.1000215

Copyright: (c) 2015 Hýsková V, et al. This is an open-access article distributed under the terms of the Creative Commons Attribution License, which permits unrestricted use, distribution, and reproduction in any medium, provided the original author and source are credited. 


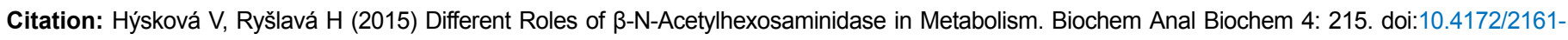
1009.1000215

5. Ficko-Blean E, Boraston AB (2006) The interaction of a carbohydrate-binding module from a Clostridium perfringens $\mathrm{N}$-acetyl- $\beta$-hexosaminidase with its carbohydrate receptor. J BiolChem 281: 37748-37757.

6. Katta S, Ankati S, PodileAR (2013) Chitooligosaccharides are converted to $\mathrm{N}$-acetylglucosamine by $\mathrm{N}$-acetyl- $\beta$-hexosaminidase from Stenotrophomonas maltophilia. FEMS MicrobiolLett 348: 19-25.

7. Ruhela D, Kamthan M, Saha P, Majumdar SS, Datta K, et al. (2015) In vivo role of Candida albicans $\beta$-hexosaminidase (HEX1) in carbon scavenging. MicrobiologyOpen 4: 730-742.

8. Plihal O, Sklenar J, Hofbauerova K, Novak P, Man P, et al. (2007) Large propeptides of fungal $\beta-\mathrm{N}$-acetylhexosaminidases are novel enzyme regulators that must be intracellularly processed to control activity, dimerization, and secretion into the extracellular environment. Biochemistry 46: 2719-2734.

9. Ryslava H, Kalendova A, Doubnerova V, Skocdopol P, Kumar V, et al. (2011) Enzymatic characterization and molecular modeling of an evolutionarily interesting fungal $\beta-\mathrm{N}$-acetylhexosaminidase. FEBS J 278: 2469-2484.

10. Chen LC, Chung YC, Chang YM, Chang CT (2011) Characterisation of a $\beta-N-$ acetylhexosaminidase from a commercial papaya latex preparation. Food Chem 124: 1404-1410.

11. Jin YL, Jo YY, Kim KY, Shim JH, Kim YW, et al. (2002) Purification and characterization of $\beta-\mathrm{N}$-acetylhexosaminidase from rice seeds. J BiochemMolBiol 35: 313-319.

12. Ghosh S, Meli VS, Kumar A, Thakur A, Chakraborty N, et al. (2011) The N-glycan processing enzymes $\alpha$-mannosidase and $\beta$-D-N-acetylhexosaminidase are involved in ripening-associated softening in the non-climacteric fruits of capsicum. J Exp Bot 62: 571-582.

13. Meli VS, Ghosh S, Prabha TN, Chakraborty N, Chakraborty S, et al. (2010)
Enhancement of fruit shelf life by suppressing $\mathrm{N}$-glycan processing enzymes. Proc Nat AcadSci USA 107: 2413-2418.

14. Jagadeesh $B H$, PrabhaTN (2002) $\beta$-Hexosaminidase, an enzyme from ripening bell capsicum (Capsicum annuum var. variata). Phytochemistry 61: 295-300.

15. Cao LJ, Zhao CP, Su SX, Luo C, Han MY (2014) The role of $\beta$-hexosaminidase in peach (Prunus persica) fruit softening. SciHorticul 169: 226-233.

16. Strasser R, Singh J, Bondili JS, Schoberer J, Svoboda B, et al. (2007) Enzymatic properties and subcellular localization of Arabidopsis $\beta-\mathrm{N}$ acetylhexosaminidases. Plant Physiol 145: 5-16.

17. Giordani R, Benyahia S, Teissere M, Noat G (1992) Purification and properties of $\mathrm{N}$-acetyl- $\beta$-D-glucosaminidase from Hevea brasiliensis latex. Plant Sci 84 : 25-34.

18. Bolar JP, Norelli JL, Harman GE, Brown SK, Aldwinckle HS (2001) Synergistic activity of endochitinase and exochitinase from Trichoderma atroviride (T-harzianum) against the pathogenic fungus (Venturia inaequalis) in transgenic apple plants. Transgenic Res 10: 533-543.

19. Dowd PF, Johnson ET, Pinkerton TS (2007) Oral toxicity of $\beta-\mathrm{N}$-acetyl hexosaminidase to insects. J Agric Food Chem 55: 3421-3428.

20. Jordan ND and Barber MS (1995) Multiple forms of wheat leaf N-acetyl- $\beta-D-$ hexosaminidase. Plant Sci 107: 41-48.

21. Ryslava H, Valenta R, Hyskova V, Krizek T, Liberda J, et al. (2014) Purification and enzymatic characterization of tobacco leaf $\beta$ - $\mathrm{N}$-acetylhexosaminidase. Biochimie 107: 263-269.

22. Krizek T, Doubnerova V, Ryslava H, Coufal P, Bosakova Z (2013) Offline and online capillary electrophoresis enzyme assays of $\beta$-N-acetylhexosaminidase. Anal BioanalChem 405: 2425-2434. 